\title{
Frames Per Second
}

National Cancer Institute

\section{Source}

National Cancer Institute. Frames Per Second. NCI Thesaurus. Code C106524.

A unit of measure equal to the number of visual frames per unit of time equal to one second. 